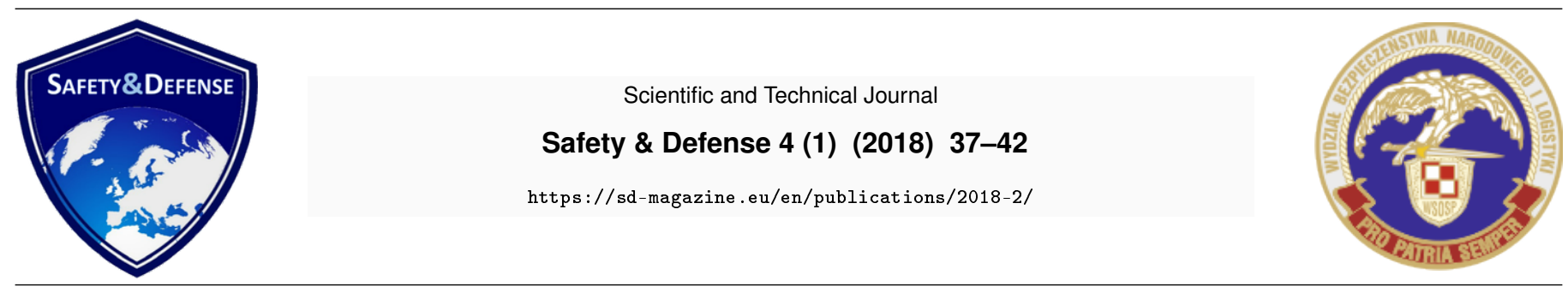

\title{
Air Transport of Explosives - Modern Solutions
}

\author{
Kamila Herc*, Barbara Zakrzewska \\ National Security and Logistics Faculty, Polish Air Force Academy, ul. Dywizjonu 303 nr 35, 08-521 Dęblin, Poland
}

\begin{abstract}
The paper is an introduction into the area of hazardous materials transportation. It includes the description of hazardous materials, classification of hazardous materials, and the list of documents necessary for organizing transport of such materials, as well as the advantages and disadvantages of air transport of hazardous materials, and identification and resolution of problems.

The aim of the article is to present the up-to-date information on air transport of explosives in the Polish Army, to identify the problems encountered during the transport preparation process, and to discuss the solution that may improve the current state of affairs. The improvements proposed by the authors include: improvement of dangerous goods labeling, introduction of Polish instructions and transport documents in the Polish Armed Forces, and training of the personnel handling transport in Poland.

The proposed solution, when implemented, would help to reduce mistakes in labeling goods, enhance the training process of personnel handling transport, as well as to facilitate the preparation of transport documentation. The starting point for the proposed results came from own research, interviews with specialists dealing with the transport of hazardous materials, including explosives, as well as international transport manuals and instructions.
\end{abstract}

Keywords: air transport, dangerous materials, explosives

\section{Introduction}

Transport of hazardous materials is a special type of transport because the transported goods contain substances that are harmful to health, the environment or directly threaten human life as a result of irradiation with radioisotopes, poisoning with gases, or being burnt with caustic substances. It requires special precautions from the packaging process to loading, transporting and unloading, and the operations are strictly defined by international standards and instructions. Due to the listed threatening situations, it is important to devote a lot of attention to transport safety, as well as avoiding mistakes that could be the direct cause of the disaster. Therefore, the authors of the article decided to look for solutions that could improve the preparation of both goods and personnel responsible for setting up the cargo. The paper depicts the procedure of transporting explosives in the Polish Army, and provides a description of hazardous materials, classification of hazardous materials, documents necessary

${ }^{*}$ Corresponding author

Email address: $\mathrm{k}$.herc3938@wsosp.edu.pl (Barbara Zakrzewska) to organize transport, advantages and disadvantages of air transport of dangerous materials, and identification and solutions to the problems pertinent to the issue.

\section{Characteristics of Dangerous Goods}

Hazardous materials are articles or substances which properties may endanger health, safety, property or the environment. They are listed on the DGR hazardous materials list or are classified in accordance with these provisions, and their description is included in the relevant regulations. The carriage of hazardous materials is subject to special IATA Dangerous Goods Regulations (which are interpreted by regulations developed by the ICAO Committee of Experts of the International Civil Aviation Organization). Some materials have been identified as too dangerous for air transport, while others may only be allowed if there is consent of the states involved in the carriage; some of these materials are only allowed on cargo planes. [1] One of the types of materials that are allowed only in cargo aircraft are explosives.

There are nine classes of hazardous materials:

1. explosives, 


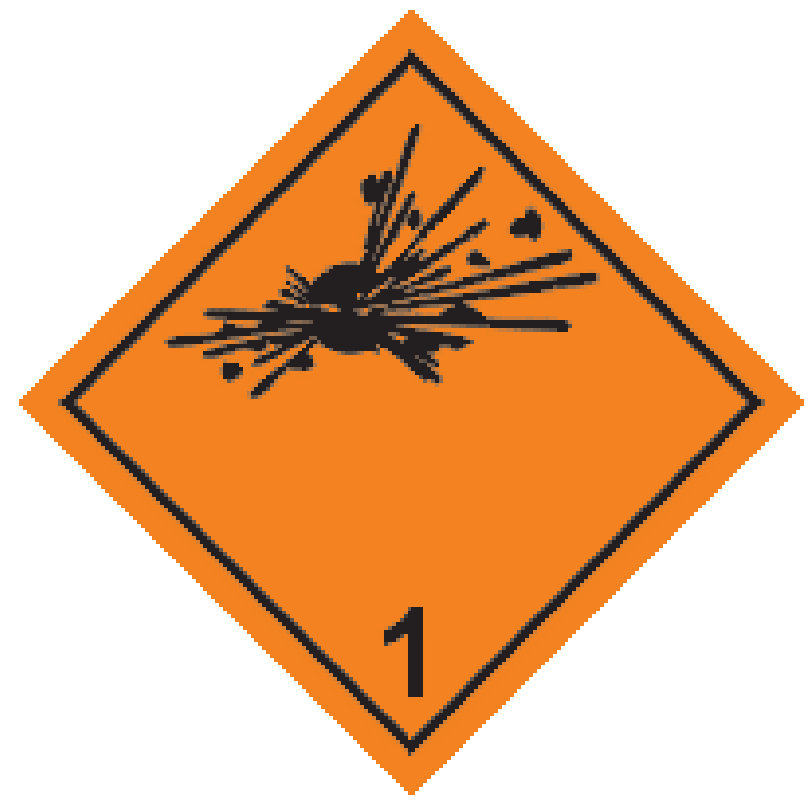

Figure 1: Safe transport of hazardous materials by air, source: Urząd Lotnictwa Cywilnego, (2017).

2. gases,

3. flammable liquids,

4. flammable solids,

5. oxidizing substances,

6. poisonous and infectious substances,

7. radioactive materials,

8. corrosive substances,

9. other hazardous materials. [1, 1490]

\subsection{Characteristic of class number one - explosives}

The main focus of the article is the first category from the above list of hazardous materials, namely explosives.

Dangerous goods have been classified with the use of the criteria of size of threat they pose into the six following subclasses:

- Subclass 1.1: Mass explosion hazard.

- Subclass 1.2: Projection hazard, no mass explosion hazard.

- Subclass 1.3: Fire hazard with either a minor blast hazard, minor projection hazard or both, no mass explosion hazard.

- Subclass 1.4: Small hazard, explosion effects confined to package.

- Subclass 1.5: Mass explosion hazard, very insensitive.

- Subclass 1.6: Extremely insensitive article, no mass explosion hazard. [2, B-11]

\section{Characteristics of Air Transport of Dangerous Goods}

Air transport is a special type of transport because the flight operations are influenced by factors that can damage the transported goods on board the aircraft, such as changing pressure in the cargo area and turbulence due to which the packaging may become unsealed, and transported materials can damage the aircraft and hurt the crew. To develop regulations regulating and supervising air traffic safety the International Air Transport Association (IATA) and the International Civil Aviation Organization (ICAO) were established. The document regulating air transport for the Armed Forces of the Republic of Poland follows the regulations defined by the American Air Force manual entitled "Air Force Manual 24-204. Preparations materials for military air shipments". [3] In Poland, classified military aircraft are used for military transports: small aircraft - M-28 Bryza, medium C-295 CASA, and large C-130 Hercules. It is permissible to transport hazardous materials by passenger carriers if the following conditions are met: the captain is informed what goods had been loaded onto the aircraft, in which containers hazardous materials are placed, in which cargo compartments, on what route they are transported. In order for the hazardous material to be accepted for transport, it must be suitably packed in accordance with the rules of packaging, properly labeled, marked, and documented. The transport personnel should consist of the sender, carrier, recipient, shipper and packer. The total quantity cannot exceed the quantitative limits and must be accompanied by appropriate transport documentation, deviations or certificates issued by the appropriate authorities. Based on interviews conducted with companies dealing with the transport of dangerous goods, conclusions were drawn that one of the most common mistakes made by senders was incorrect marking of shipments that did not have the required markings on the specificity of hazardous properties, and some did not have any indication that the shipment is dangerous goods. These mistakes may result from the lack of sufficient knowledge of senders in the matter of packing dangerous goods or ignorance of security procedures.

\subsection{Documents necessary for organizing transport}

The documents are in paper and should be filled in by the sender. When transporting dangerous goods by air, it is necessary to meet the following conditions:

1. 1. An appropriate entry is required on the consignment note (MAWB) (Master Air Way Bill).

2. Additional document - sender's declaration for dangerous goods (Shipper's Declaration for Dangerous Goods).

In the declaration SHIPPER'S DECLARATION FOR DANGEROUS GOODS there is information about:

- goods route,

- sender's details, 
- recipient,

- departure and arrival ports,

- type of aircraft,

- information about dangerous goods,

- UN number,

- correct shipping name,

- quantity,

- way of packing,

- type of packaging,

- packing instruction.

The regulations clearly define the scope, form, and manner of providing this data. The official language in the transport of dangerous goods by air is English, so all entries must be in this language. Other languages are also allowed, but English translation must always be prepared and included in all documents. If it is planned to transport hazardous materials outside the country, documented consent of states is needed to fly over the territory through which the transport will be carried out. The Armed Forces of the Republic of Poland do not have a document of their own authorship, therefore they use the one proposed by the American Air Force Manual 24 204, ICAO, IATA [3]. Currently, work to develop a Polish document modeled on previously used international instructions is in progress.

\subsection{Advantages and Disadvantages of Air Transport of Haz- ardous Materials}

Undoubtedly, the advantage of the greatest weight is a much shorter time of transporting goods than with other means of transport. Goods arrive in a few hours from the point of departure to the destination. In comparison, the road, rail, or sea transport would take significantly more time, for example, in the case of road transport, frequent traffic jams slow the transport down, and for rail or sea transport low speed is a general characteristics. Moreover, air transport is characterized by a high safety factor compared to other modes of transport. For comparison, when transporting by road, the risk of accidents occurrence is high, in consequence of which the goods or packaging may be damaged. In the worst situation there may be an explosion of goods whose firepower may contribute to the injuries or even deaths of many people, and also cause high material losses. During air transport, there is a small risk of damage to the packaging and the goods, as well as causing any dangerous situation, for example, explosion. Occasional turbulence is usually not a problem and it poses no real threat.

The biggest disadvantage of transporting goods containing explosives are legal regulations that require carrying out complex procedures, so the operators have to be very involved in the process and focused in order not make any mistakes. The Polish Army is currently is using an American document regulating air transport of explosives. In consequence, the Polish staff must be sent to the United States to get the necessary permits. Another difficulty is related to the labeling of shipments. Goods are often incorrectly marked or do not contain correct information, and sometimes they do not have information about dangerous properties of the cargo. In addition, some states do not allow goods that contain explosives or, more generally, hazardous materials to transport over their territory, which results in longer flight paths. The issue of air terrorism is worthy to mention here because hijacking a cargo airplane transporting such materials may become an easy and valuable target for terrorists because an aircraft containing hazardous materials can cause enormous losses. Damage of radioactive materials can bring forth radioactive contamination; the leak of chemical substances pose a serious threat to the crew's health and may lead to the contamination of the area over which the plane passes or lands. On the other hand, shooting down an aircraft containing goods with explosives may result in a large-scale explosion.

\section{Identification and Solutions to the Problems}

\subsection{Identification of dangerous goods}

As mentioned already, one of the most urgent problems is improperly marked dangerous goods, as a solution to which can be using the barcode identification. The proposed procedure is a method of putting a barcode sticker on the packaging of a given shipment, which would contain all the information necessary for the personnel loading the goods, so they can load the goods onto the aircraft without any doubts or mistakes. The bar code would contain: sender and recipient address, material name, UN designation, security class and subclass, and the packing group. For example, a two-dimensional variable length DataMatrix bar code can be used. The advantages of the selected code are the high information capacity on a small area and the ability to read data with up to $25 \%$ damage of the code.

The use of innovations would certainly help to facilitate the loading process by reducing unnecessary activities related to checking the shipment, because the check would consist only of scanning cargo with the code reader. The likelihood of loading goods with incomplete information on the plane would also be reduced, as the code would have all the necessary information. However, the traditional, regular label would not be eliminated - the bar codes would be treated as an auxiliary and streamlining measure.

\subsection{Introduction of Polish instructions and transport docu- ments in the Polish Armed Forces}

The most appropriate solution to unify the instructions and documentation, as well as to simplify the transport processes is to introduce Polish instructions containing procedures for air transport of dangerous goods. The document would be 


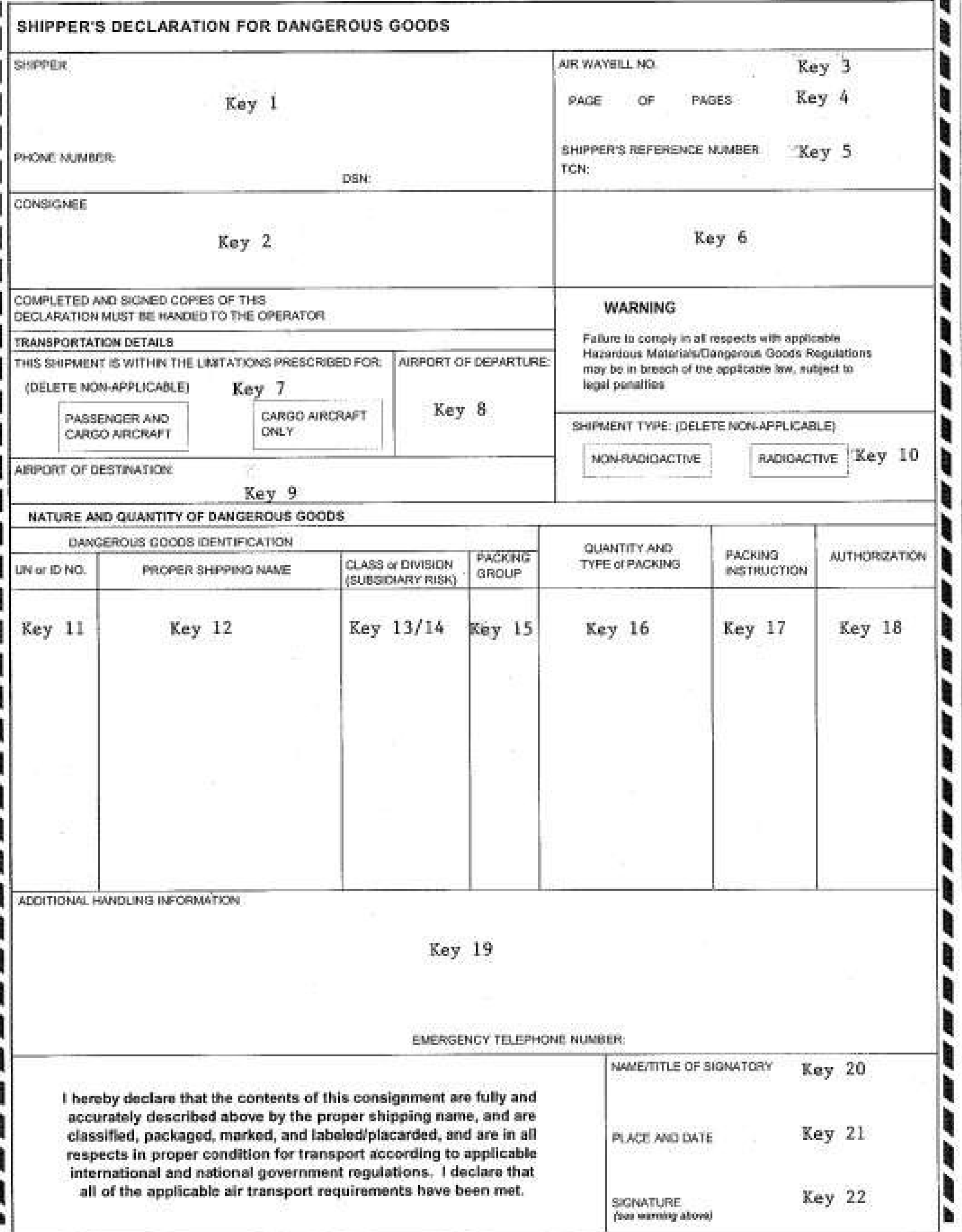

Figure 2: Template of a military transport document, source: Air Force Manual 24-204 [3] 


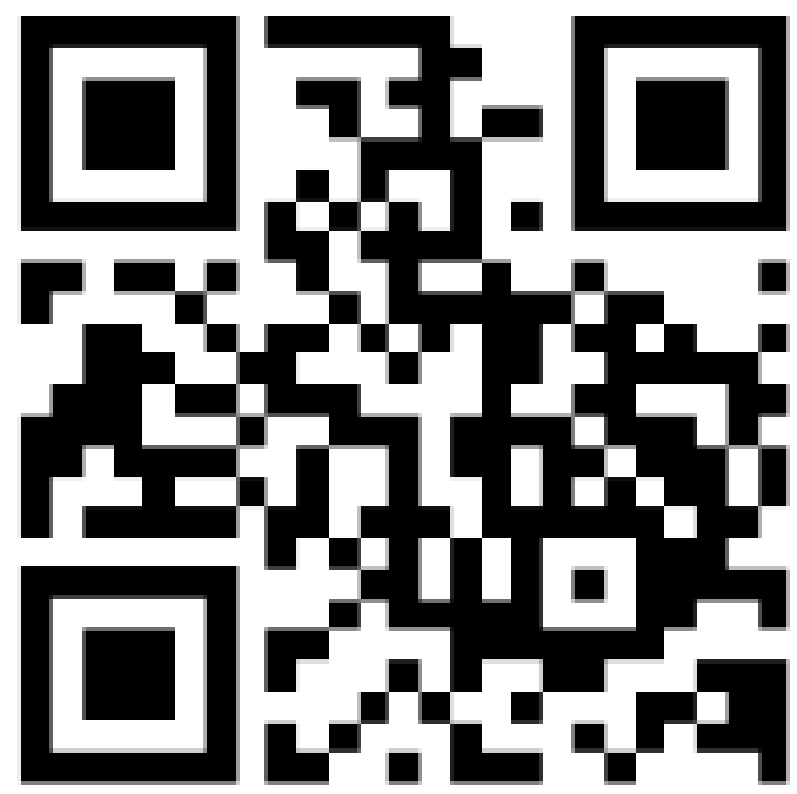

Figure 3: DataMatrix Code, source: Kody kreskowe GS1

based on the currently valid documents, i.e. Air Force Manual 24 - 204, IATA DGR, and ICAO. The information contained would concern procedures related to the general rules and safety of transport. The transport documents should be prepared in English. However, bilingual documents, namely in Polish and English would be a better idea because they would be easier to use and hence reduce the number of mistakes. Specification and the number of documents is determined by the number of people who would need them depending on their specific positions. Individuals who can send and receive documents should be included. In the Polish Armed Forces, explosives transports are carried out by the 3rd Wing of the Aviation Transport in Powidz, while in Wrocław there is an Airport Operations Complex from the Airport Handling Command Wroclaw, which is subordinate to the Third Wing. Their main task is to transport ammunition rifles of various caliber. Another simplification could be the Polish version of the IATA manual. The organization already provides the manual in various national languages such as French, Russian, Spanish (ordering such a translation would however involve high costs and the manual has a two-year expiration date). The introduction of instructions and documents in Polish would certainly help to reduce mistakes in the preparation of transport and would be a streamlining shortening the time of transport.

\subsection{Training of personnel handling transport}

Currently, training takes place in the United States or is organized by American delegations in Poland. The courses and exams are held in English. Learning only in English is not easy and further complicates the process of acquiring the required knowledge and skills. Moreover, international manuals, such as IATA DGR, are also, as mentioned before, written in English. The introduction of Polish-language training would certainly contribute to the more effective acquisition of knowledge in this matter and would reduce to a certain extent the time of conducting the course. Still, the exam has to be taken in English. Another crucial issue regarding the training is the high costs. The main expenses for students consist mainly of food, accommodation, and the cost of the course. These are basic expenses that accompany every training. However, the transport of Polish soldiers over two thousand kilometers to the destination where the course takes place generates considerable expenses. In addition, the costs of living and accommodation are much higher in the U.S., than in Poland. Organizing a training in Poland would be possible by carrying out an additional course for people who are to train future personnel servicing air transport by a delegation from the United States Air Force. The best solution would be to have both courses in Poland in one of the military bases. Due to the availability of school and airport infrastructure, the 41st Aviation School Base in Dęblin suits perfectly this purpose. Polish-language training carried out by Polish soldiers in the country would certainly become not only a more practical or more convenient, but also less expensive than today.

\section{Conclusions}

The authors are of the opinion that the abovementioned improvements have the potential and should to be implemented due to the safety and practical reasons discussed above. Examples of improvements in the labeling of packages, the introduction of the Polish language training course, and having the manual written in Polish should help to get rid of the most common problems occurring during the transport of dangerous goods. The deployment of the abovementioned improvements would certainly contribute to the reduction of the risk of improperly marked goods being loaded onto the aircraft because by entering information into a bar code there is little probability of a mistake. The Polishlanguage form of the training course would improve the quality of the training and the students would be able to acquire the necessary knowledge faster and easier; additionally, the costs of the course, if carried out in Poland, would be much smaller. Having Polish-language documents would facilitate the implementation of transport processes, so that the time spent on drafting documentation would be much shorter. In conclusion, according to the authors, the introduction of the above-mentioned improvements would enhance the efficiency of the processes for transporting explosives by air by the Polish Army.

\section{References}

[1] A. Kwasiborska, Przewozy materiałów niebezpiecznych transportem lotniczym, Logistyka 3 (2011) 1439-1494.

[2] ICAO, Technical Instructions for the Safe Transport of Dangerous Goods by Air, Appendix B, accessed: (28.11.2017) (2016).

URL https : / /www . icao. int/safety/dangerousgoods/working $\% 20$ group $\% 20$ of $\% 20$ the $\% 20$ whole/wp. 50 .appb.pdf 
[3] DAF [Department of the Air Force], Air Force Manual 24-204, accessed: (28.11.2017) (2017).

URL http://static.e-publishing.af .mil/production/1/af_a4/

publication/afman24-204/afman24-204.pdf 